\title{
ROLE OF IMAGING IN ACUTE ABDOMEN IN ADULT
}

By

\begin{abstract}
Ahmed Mahmoud Helmy Mohammed, Abd El-Monem Sayed Ragheb, Mahmoud Kadry El-Gendy and Mohamed Abu El-Naga Mohamed
\end{abstract}

Department of Radio diagnosis, Faculty of Medicine, Al-Azhar University

Corresponding author: Ahmed Mahmoud Helmy Mohammed,

Mobile: (+20) 01027594945, E-mail: ahmed_helmy@gmail.com

\begin{abstract}
Background: Acute abdominal pain is a common complaint of patients presenting at the Emergency Department. Approximately, $10 \%$ of presentations at the Emergency Department are because of acute abdominal pain which can be caused by a variety of diseases ranging from mild and self-limiting to lifethreatening diseases.
\end{abstract}

Objective: The purpose of this study was to collect data for constructing an optimal diagnostic algorithm for the wide spectrum of patients with acute abdominal pain at the Emergency Department (ED).

Patients and methods: The study was carried out at the Department of Radiology, Al-Azhar University Hospitals, Cairo. The study was carried during the period between April 2019 and April 2020 a total of 30 patients were selected from those were referred to Radiology Department of Al-Azhar University Hospitals. All patients were subjected to conventional radiography, US and CT scan.

Results: Out of 30 patients, there were 15 (50\%) male patients, 15 (50\%) female patients. The spectrum of diseases included in the study were bowel obstruction (23.3\%), obstetric related causes (20.0\%), urinary cause (20.0\%), acute appendicitis (13.3\%), abdominal malignancy (3.3\%), acute cholecystitis (3.3\%), Chron's disease $(3.3 \%)$, hepatic abscess $(3.3 \%)$, pancreatitis $(3.3 \%)$, perforated viscus $(3.3 \%)$ and splenic abscess (3.3\%).

Conclusion: Radiological assessment has a main role in diagnosis and treatment of acute abdomen. CT proved to be a better imaging modality with high sensitivity and specificity in diagnosis than conventional imaging especially in acute appendicitis, Chron's disease, hepatic abscess, pancreatitis and splenic abscess. $\mathrm{X}$-ray was the standard in diagnosis of intestinal obstruction or viscus perforation.

Keywords: Abdominal pain, ED, CT, X-ray.

\section{INTRODUCTION}

An early and accurate diagnosis results in more accurate management and, subsequently, leads to better outcomes. Causes for acute abdominal pain can be classified as urgent or nonurgent. Urgent causes require immediate treatment (within 24h) to prevent complications; whereas for nonurgent causes, immediate treatment is not necessary. Most common urgent causes are acute appendicitis, acute diverticulitis, and bowel obstruction. Most common nonurgent causes are nonspecific abdominal pain (NSAP) and gastrointestinal diseases (Fagerstroem et al., 2017).

Complaints of acute abdominal pain can be very nonspecific at the start and evolve to more disease-specific symptoms over time. This increases the difficulty of 
an accurate identification of the cause of acute abdominal pain. The first step in the diagnostic pathway is clinical evaluation. In daily practice, a preliminary diagnosis will be made based on medical history, physical examination, and, in some cases, laboratory parameters. After clinical assessment, the decision can be made to perform additional diagnostic investigations to increase certainty of the diagnosis (Gans et al., 2016).

The use of additional imaging modalities such as plain radiography, ultrasound, and computed tomography (CT) has increased over the years. Only a few decades ago, when imaging was not widely available and its diagnostic accuracy was low, patients would immediately proceed to the operating theater. However, many causes can be treated conservatively and do not benefit from diagnostic laparoscopy and laparotomy (Gans et al., 2015).

The increase in use of diagnostic modalities also has downsides. Imaging can lead to higher costs, a protracted patient throughput at the emergency department, and an increased risk of negative side effects such as contrastinduced nephropathy and ionizing radiation exposure. To date, the effect of the increased use of imaging on cost effectiveness of treatment of patients with acute abdominal pain remains unknown (Laméris et al., 2017).

Despite the increased use of imaging modalities, acute abdominal pain remains a major diagnostic challenge. The underlying cause for the acute abdominal pain can be in the area of many different specialties such as gynecology, surgery, internal medicine, and urology. This leads to a large variation in choice of diagnostic modalities and treatment. Diagnostic practice varies within hospitals and within specialties, mostly lead by a doctor's preferences (Mayumi et al., 2015).

This guideline was developed to standardize the diagnostic pathway of patients with acute abdominal pain and provide doctors with evidence-based support in their decisionmaking process. A multidisciplinary steering group developed the national guideline based on all available international literature regarding the diagnostic pathway in patients with acute abdominal pain, making the guideline internationally applicable (Velissaris et al., 2017).

The purpose of this study was to collect data for constructing an optimal diagnostic algorithm for the wide spectrum of patients with acute abdominal pain at the emergency department (ED).

\section{PATIENTS AND METHODS}

This prospective study comprised of 30 patients with acute abdomen that were investigated abdominal ultrasound, X-ray and a spiral CT scan at the Radiology Department, Al-Azhar University Hospitals. Ethical approval from Al-Azhar University Ethics Committee was obtained. The study was carried during the period between April 2019 and April 2020.

\section{Inclusion criteria:}

Patients with abdominal pain with duration of $>2$ hours and $<5$ days presenting at the ED.

\section{Exclusion criteria:}

Age $<18$ years, pregnancy, abdominal pain due to blunt or penetrating trauma, 
hemorrhagic shock caused by gastrointestinal bleeding or ruptured aortic aneurysm and patients in whom no imaging was warranted by the treating physician and who were subsequently discharged home from the ED.

Initial examination was consisting of standardized clinical history, physical and laboratory examination. Subsequently, an abdominal ultrasound, a supine abdominal X-ray, an upright chest X-ray and a spiral CT scan were performed.

The diagnostic tests were performed in a standardized way. Abdominal ultrasound scanning was systematically investigating the entire abdomen for general and organ specific anomalies. Both positive and negative findings were recorded of all variables listed in the case record form. A curved 3.5-5.0 $\mathrm{MHz}$ array and a linear $10 \mathrm{MHz}$ array were used.

All abdominal CT scans were performed using a multi detector row 4 or 16 slice helical CT scanner. The model CT scan protocol consist a scan with an effective A level of 165 , and $120 \mathrm{kV}$, collimation: $2.5 \mathrm{~mm}$, slice width: $3 \mathrm{~mm}$, rotation time: $0.5 \mathrm{~s}$. Intravenous contrast (125ml.ultravist) was injected at $3 \mathrm{ml} / \mathrm{s}$. Scanning started after 60 seconds. Nooralor rectal contrast agents were used. All results, including findings and diagnosis after initial examination, were recorded in dependently of previous results and other findings.

Both positive and negative findings were recorded of all variables listed in a separate case record form.

Case Record Forms (CRF) was facilitating the standardization of clinical history, physical examination, laboratory parameters and radiological examination. After clinical history, physical and laboratory examination, the three most likely diagnoses, a level of confidence of the most likely diagnosis and a management plan was recorded by the treating physician. Subsequently, a differential diagnosis, level of confidence of the most likely diagnosis and a management plan was recorded separately after US, after plain X-ray, and finally after $\mathrm{CT}$.

Chest and abdominal X-rays was evaluated by the treating physician. Both US and CT were performed and evaluated by radiology residence or radiologists, blinded for each other's test results and for the test results of the abdominal and chest X-rays. Summarized clinical findings, as in routine practice, were provided to the radiologist. The radiologist performing the ultrasound recorded the findings in the patients CRF with general and organ-specific US findings ending with a differential diagnosis with a level of confidence of the most likely diagnosis. Another radiologist evaluated the CT scan and recorded data in a similar way.

Four months of follow up were obtained for all patients. All available information were gathered, including course of disease, laboratory findings, operation reports, pathology reports, treatment out come and costs.

All included patients were evaluated using a uniform reference standard not dependent of the index tests results. Expert panel was reviewing each case and assign the final diagnosis. Cases were presented in a standardized way, including all available follow-up data gathered as 
mentioned above. Panel members evaluated cases individually, after which consensus reached in group discussion.

\section{Statistical analysis:}

Recorded data were analyzed using the statistical package for social the sciences, version 20.0 (SPSS Inc., Chicago, Illinois, USA). Quantitative data were expressed as mean \pm standard deviation (SD).
Qualitative data were expressed as frequency and percentage. Chi-square (x2) test of significance was used in order to compare proportions between two qualitative parameters. The confidence interval was set to $95 \%$ and the margin of error accepted was set to $5 \%$. The p-value was considered significant when P-value $<0.05$.

\section{RESULTS}

This study included 30 patients. It was conducted in radiology department of AlAzhar university hospitals. Mean age of patients was $38 \pm 13$ (Mean \pm SD) with minimum of 19 years old and maximum of 67 years old. Fifteen of our sample was males and 15 were females. Smoking was present in $13(43.3 \%)$ of patients. Diabetes was present in $9(30 \%)$ of patients. Also, hypertension was present in $9(30 \%)$ of patients. Bowel obstruction was found in $23.3 \%$ of cases, obstetric related causes
$20.0 \%$, urinary causes $20.0 \%$, acute appendicitis $\quad 13.3 \%, \quad$ abdominal malignancy $3.3 \%$, acute cholecystitis $3.3 \%$, Chron's disease $3.3 \%$, hepatic abscess $3.3 \%$, pancreatitis $3.3 \%$, perforated viscus $3.3 \%$ and splenic abscess $3.3 \%$. Bowel obstruction, Obs/Gyna related causes, urinary cause and acute appendicitis were the most common diagnoses in our sample (Table 1).

Table (1): Clinical Findings

\begin{tabular}{|l|c|c|c|c|}
\hline Parameters & Mender & Fale & Female & \multicolumn{2}{c|}{ Total (n, \%) } \\
\hline Bowel obstruction & 6 & 1 & 7 & $23.3 \%$ \\
\hline Obs/Gyna related & 0 & 6 & 6 & $20.0 \%$ \\
\hline Urinary cause & 3 & 3 & 6 & $20.0 \%$ \\
\hline Acute appendicitis & 2 & 2 & 4 & $13.3 \%$ \\
\hline Abdominal malignancy & 1 & 0 & 1 & $3.3 \%$ \\
\hline Acute cholecystitis & 0 & 1 & 1 & $3.3 \%$ \\
\hline Chron's disease & 1 & 0 & 1 & $3.3 \%$ \\
\hline Hepatic abscess & 1 & 0 & 1 & $3.3 \%$ \\
\hline Pancreatitis & 0 & 1 & 1 & $3.3 \%$ \\
\hline Perforated viscus & 1 & 0 & 1 & $3.3 \%$ \\
\hline Splenic abscess & 0 & 1 & 1 & $3.3 \%$ \\
\hline
\end{tabular}

Diagnostic findings in every clinical condition were illustrated. US, X-ray and
CT were presented in a comparative manner (Table 2). 
Table (2): Diagnostic findings in every clinical condition

\begin{tabular}{|c|c|c|c|}
\hline $\begin{array}{l}\text { Diagnosis } \\
\text { Conditions }\end{array}$ & US & X-ray & CT \\
\hline Acute appendicitis & $\begin{array}{l}\text { Non-compressible } \\
\text { dilated appendix }\end{array}$ & & $\begin{array}{l}\text { Appendicular } \\
\text { dilatation }\end{array}$ \\
\hline Bowel obstruction & $\begin{array}{l}-\quad \text { Dilated } \\
\text { whirling appearance } \\
\text { - dilated loops } \\
\text { with to and fro } \\
\text { movement }\end{array}$ & $\begin{array}{l}-\quad \text { barium } \\
\text { enema: bird peak } \\
\text { sign-x-marks-the-s } \\
\text { - colonic } \\
\text { distension } \\
\text { - dilated loops }\end{array}$ & 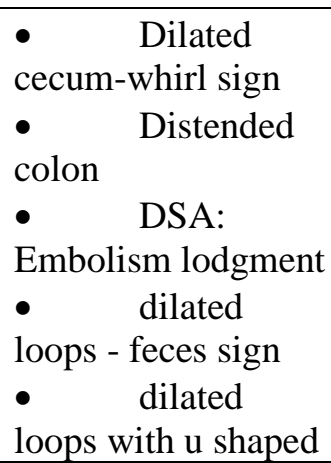 \\
\hline Obs related & 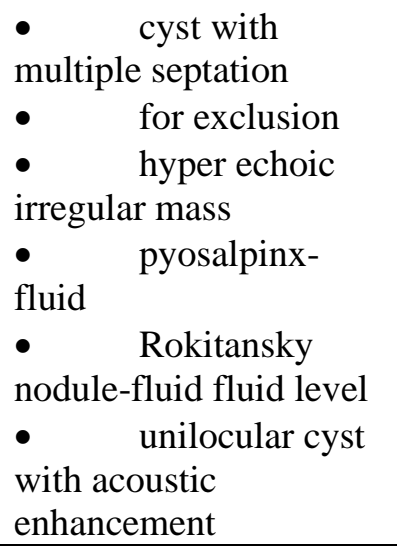 & $\begin{array}{l}\text { calcific and tooth } \\
\text { component }\end{array}$ & $\begin{array}{l}\text { - } \\
\text { cyst multilocular } \\
\bullet \quad \text { free fluid- } \\
\text { fallopian tube } \\
-\quad \text { Rokitansky } \\
\text { protuberance }\end{array}$ \\
\hline Urinary cause & $\begin{array}{l}\text { - echogenic foci } \\
\text { with acoustic shadow } \\
\text { - urin bladder } \\
\text { turbity with thick wall }\end{array}$ & $\begin{array}{l}-\quad \text { radio opaque } \\
\text { stone }\end{array}$ & $\begin{array}{l}-\quad \text { halo sign - } \\
\text { gastric wall edema } \\
-\quad \text { radio } \\
\text { opaque stone }\end{array}$ \\
\hline $\begin{array}{l}\text { Abdominal } \\
\text { malignancy }\end{array}$ & & $\begin{array}{l}\text { barium enema: soft } \\
\text { tissue density with } \\
\text { ulcer }\end{array}$ & \\
\hline Acute cholecystitis & $\begin{array}{l}\text { Cholelithiasis - thick } \\
\text { wall }\end{array}$ & & $\begin{array}{l}\text { cholelithiasis -fluid } \\
\text { collection }\end{array}$ \\
\hline Chron's disease & $\begin{array}{l}\text { increased sup } \\
\text { mesenteric artery flow } \\
\text { volume }\end{array}$ & barium follow throw & fat halo sign \\
\hline hepatic abscess & $\begin{array}{l}\text { poorly demarcated hypo } \\
\text { echoic }\end{array}$ & - & double target sign \\
\hline pancreatitis & & & $\begin{array}{l}\text { non-enhancing low } \\
\text { attenuation }\end{array}$ \\
\hline Perforated viscus & $\begin{array}{l}\text { bright bowel out } \\
\text { pouching }\end{array}$ & & pericolic stranding \\
\hline splenic abscess & $\begin{array}{l}\text { poorly demarcated hypo } \\
\text { echoic }\end{array}$ & & central low density \\
\hline
\end{tabular}

DSA: digital subtraction angiography 
Difference between diagnostic positive cases were collected in Table (3). modalities X-ray, US and CT in detecting

Table (3): Difference between diagnostic modalities

\begin{tabular}{|l|c|c|c|c|}
\hline \multicolumn{1}{|c|}{ Pereweters } & $\begin{array}{c}\text { Total } \\
\text { real cases }\end{array}$ & X-ray & US & CT \\
\hline Acute appendicitis & $\mathbf{4}$ & $\mathbf{0}(\mathbf{0 \%})$ & $\mathbf{3 ( 7 5 \% )}$ & $\mathbf{4 ( 1 0 0 \% )}$ \\
\hline Obs related & $\mathbf{6}$ & $\mathbf{1 ( 1 6 . 6 7 \% )}$ & $\mathbf{6 ( 1 0 0 \% )}$ & $\mathbf{3 ( 5 0 \% )}$ \\
\hline Urinary cause & 6 & $1(16.67 \%)$ & $2(33.33 \%)$ & $2(33.33 \%)$ \\
\hline Bowel obstruction & 7 & $7(100 \%)$ & $2(28.57 \%)$ & $7(100 \%)$ \\
\hline
\end{tabular}

Sensitivity of US and CT in diagnosis of acute appendicitis was $75 \%$ and $100 \%$ respectively (Table 4).

Table (4): Sensitivity of US and CT in diagnosis of acute appendicitis

\begin{tabular}{|c|c|c|c|c|}
\hline Appendicitis & $N$ & US (\%) & CT $(\%$, CI $)$ & $p$ values \\
\hline Sensitivity & 4 & $75 \%(19.41-99.37$ & $100 \%(39.76-100)$ & $>0.05$ \\
\hline
\end{tabular}

Sensitivity of US and X-ray in diagnosis of bowel obstruction was $28.57 \%$ and $100 \%$ respectively (Table (5).

Table (5): Sensitivity of US and x-ray in diagnosis of Bowel obstruction

\begin{tabular}{|c|c|c|c|c|}
\hline Bowel obstruction & $\mathrm{N}$ & X-ray and CT (\%) & US (\%, CI) & p values \\
\hline Sensitivity & 7 & $100 \%$ & $28.57 \%(3.67-70.96)$ & $>0.05$ \\
\hline
\end{tabular}

Sensitivity of US and CT in diagnosis of Gynecological causes of abdominal pain was $100 \%$ and $50 \%$ respectively (Table (6).

Table (6): Sensitivity of US and CT in diagnosis of Gynecological causes of abdominal pain

\begin{tabular}{|c|c|c|c|c|}
\hline Gynecological causes & $N$ & US (\%) & CT $(\%, C I)$ & $p$ values \\
\hline Sensitivity & 6 & $100 \%$ & $50 \%(11.81-88.19)$ & $>0.05$ \\
\hline
\end{tabular}

\section{DISCUSSION}

We performed erect standing abdomen and left lateral decubitus view. In our study, the presence of $\geq 2$ air fluid levels, differential air fluid levels in the same loop of bowel more than $2 \mathrm{~cm}$ in height and a mean air-fluid level of $>25 \mathrm{~mm}$. in width on erect abdominal radiographs there was considered highly suggestive of high grade obstruction (Ashindoitiang et al., 2012).

We were able to diagnose intestinal obstruction from plain X-ray abdomen in all $100 \%$ of patients who had intestinal obstruction. $28.57 \%$ of patients had positive ultrasonography. $3.3 \%$ had free 
intra- peritoneal air (associated small bowel perforation) on plain $\mathrm{x}$-ray erect abdomen. Those patients who had intestinal obstruction were immediately operated. On ultrasonography, there were dilated bowel loops with to and fro peristalsis in both patients. Ultrasonography results were equivocal in $3.3 \%$. Thus, plain $\mathrm{X}$ - ray abdomen erect standing was more diagnostic as compared to ultrasonography. US did not give any additional benefit than plain $\mathrm{X}$ rays abdomen.

All of those patients showed evident obstruction with dilated bowel loops and collapsed loops distal to obstruction with beak sign. Hence CT was more effective method in patients with intestinal obstruction. There were $3.3 \%$ of patients with clinical suspicion of cecal volvulus. Both were male patients. Palpable abdominal mass was present in one patient. We evaluated patients initially by ultrasonography. By USG we were able to diagnose volvulus in both patients.

Barium enema revealed peak sign in one patient. CT revealed bird peak sign-Xmarks-the-spot sign in the other patient. In one patient, plain X-ray, there were features of distal bowel obstruction. CT of the same patient showed large gas-filled loop without haustral markings, forming a closed-loop obstruction. Our findings were correlated with other study (Postma et al., 2011). Thus our study concluded that CT was a better modality than any other imaging modality in this specific diagnosis.

There was $3.3 \%$ of patients' of necrotizing enterocolitis. We investigated by plain X-ray abdomen AP view and if required lateral and left lateral decubitus views. We were able to suspect necrotizing enterocolitis in him patients by plain X-rays. Further investigation included US. On ultrasonography, color Doppler superior mesenteric artery was found to be occluded.

There were $13.3 \%$ cases of acute appendicitis in our study. Ultrasonography was able to find of them $75 \%$ which showed tubular, blind ended, noncompressible, non- peristaltic structure of mixed echogenicity in right iliac fossa with average diameter of $>6 \mathrm{~mm}$ and associated probe tenderness in right iliac fossa in 3 cases. Plain X-ray abdomen was normal in all patients. Ultrasound proved out to be most useful modality in our study than X-Ray. CT scan prove to be better than US.

Al Ajerami (2012) in his study on acute appendicitis found the overall sensitivity and specificity of ultrasound, using surgical outcome as the gold standard, to be $84.8 \%$ and $83.3 \%$ respectively. Zoller et al. (2010) in their meta-analysis demonstrated that US has sensitivity of $85 \%$ and a specificity of $96 \%$ in diagnosing acute appendicitis. According to Van Randen et al. (2011), the sensitivity in detecting acute appendicitis differed significantly between ultrasound and CT. Ultrasound sensitivity in detecting acute appendicitis was $76 \%$ versus $94 \%$ for CT.

There was $3.3 \%$ of Chron's disease. We performed barium follow throw and US. There was inflammatory thickening noted in terminal ileum, cecal and ascending colon and there were multiple enlarged mesenteric lymph nodes noted, features diagnostic of infective/ inflammatory etiology. Superior 
mesenteric artery showed increased flow volume. Cholycistitis was found in only one patient.

According to Rai et al. (2017) ultrasonography is highly accurate in gall bladder conditions, the sensitivity and specificity of ultrasonography in diagnosing pancreatic conditions was $100 \%$. This is correlated with our findings taking small sample size in our consideration. Allemann et al. (2010) reported that in US done by surgeons for patients with acute abdominal pain the correct diagnostic rate from $70 \%$ to $83 \%$. In the same study, US were found to have a sensitivity and specificity of $94 \%$ and 99\% in diagnosing biliary tract disease.

Obstetric related causes were found in $20.0 \%$ of the cases. US findings included cyst with multiple septation, hyper echoic irregular mass, pyosalpinx-fluid, Rokitansky nodule-fluid fluid level and unilocular cyst with acoustic enhancement. It was very diagnostic in these cases.

X-ray showed calcific and tooth component in one case. CT abdomen showed multilocular cyst, free fluidfallopian tube and Rokitansky protuberance.

McGrath and Keeling (2011), in their study on the role of early US in the management of the acute abdomen, concluded that it is most useful in the diagnosis of gynecological disorders.

For urgent gynaecological disorders, Van Randen et al. (2011) reported that the sensitivity was significantly higher for CT than for ultrasound: $67 \%$ versus $37 \%$. Likewise, the sensitivity in detecting inflammatory bowel disorders was higher for CT than for ultrasound. For acute cholecystitis and bowel obstruction sensitivity did not differ significantly between ultrasound and CT.

In our study, only one female patient presented with acute necrotizing pancreatitis. CT showed non-enhancing low attenuating regions within pancreas.

Manfredi et al. (2011) concluded that US in acute pancreatitis is a good screening test in patients with suspected biliary pancreatitis and a mild clinical course but contrast enhanced CT is preferred for patients with acute pancreatitis.

A prospective study was carried out by Caterino et al. (2011) the result of this study demonstrated the usefulness of emergency ultrasonography in acute abdominal conditions involving various organ systems and associated pathologies. Results obtained showed that ultrasonography is highly accurate. In majority of the systems, a definite diagnosis was made.

\section{CONCLUSION}

Radiological assessment has a main role in diagnosis and treatment of acute abdomen presented from emergency department. CT proved to be a better imaging modality with high sensitivity and specificity in diagnosis than conventional imaging especially in acute appendicitis, Chron's disease, hepatic abscess, pancreatitis and splenic abscess. $\mathrm{X}$-ray was the standard in diagnosis of intestinal obstruction or viscus perforation.

\section{REFERENCES}

1. Al-Ajerami Y. (2012): Sensitivity and specificity of ultrasound in the diagnosis of 
acute appendicitis. East Mediterr Health J., 18(1):66-9.

2. Allemann F, Cassina $P$, Rothlin $M$ and Largiader F. (2010): Ultrasound scans done by surgeons for patients with acute abdominal pain: a prospective study. Eur J Surg., 165(10): 966-70.

3. Ashindoitiang JA, Atoyebi AO and Arogundade RA. (2012): The value of plain abdominal radiographs in management of abdominal emergencies. Luth Nig Q J Hosp Med., 18(3): 170-174.

4. Caterino S, Meli C, Capotondi C, Cavallini M, Zerilli M, Schiffino L, Murante G, Alessi G and Cavallaro A. (2011): Role of ultrasonography in emergency surgery. Ann ItalChir., 66(1):87-97.

5. Fagerstroem $A$, Paajanen $P$ and Saarelainen H. (2017): Non-specific abdominal pain remains as the most common reason for acute abdomen: 26-year retrospective audlt in one emergency unit. Scandinavian Journal of Gastroenterology, 52(10):1-6.

6. Gans SL, Pols MA and Stoker J. (2015): Guideline for the Diagnostic Pathway in Patients with Acute Abdominal Pain. Dig Surg., 32:23-31.

7. Gans SL, Stoker J and Boermeester MA. (2016): Plain abdominal radiography in acute abdominal pain; past, present, and future. International Journal of General Medicine, 5: $525-533$.

8. Laméris W, RandenAV and Boermeester MA. (2017): Optimization of diagnostic imaging use in patients with acute abdominal pain (OPTIMA): Design and rationale. BMC Emergency Medicine, 7:9-12.
9. Manfredi R, Brizi MG, Canade A, Vecchioli $A$ and Marano P. (2011): Imaging of acute pancreatitis. Rays, 26(2):135-42.

10. Mayumi T, Yoshida $M$ and Furukawa A. (2015): The Practice Guidelines for Primary Care of Acute Abdomen 2015. Japanese Journal of Radiology, 23(1): 80-115.

11. McGrath FP and Keeling F. (2011): The role of early sonography in the management of the acute abdomen. ClinRadiol., 44(3):172-4.

12. Postma GN, Seybt MW, Rees CJ, Snow JB and Wackym PA. (2011): Ballinger's otolaryngology Head \& neck surgery. 22thedition. Pbl. Shelton, Conn: BC Decker Inc, Pp. 975-95.

13. Rai V, Mishra M, Pandey $Y$, Singh $P$ and Tripathi A. (2017): Diagnostic role of ultrasonography for diagnosis of acute abdomen. JMSCR., 5(8): 26609-26613.

14. Van Randen A, Laméris W, van Es HW, van Heesewijk HP, van Ramshorst B, ten Hove W and Stoker J. (2011): A comparison of the accuracy of ultrasound and computed tomography in common diagnoses causing acute abdominal pain. European Radiology, 21(7): 1535-1545.

15. Velissaris D, Karanikolas $M$ and Gogos $C$. (2017): Acute Abdominal Pain Assessment in the Emergency Department: The Experience of a Greek University Hospital. J Clin Med Res., 9(12):987-993.

16.Zoller WG, Kellner $H$ and Schwerk WB. (2010): Value of ultrasound in diagnosis of acute appendicitis. Bildgebung, 63(2):78-82. 
دور التصوير بالأشعة في ألم البطن الحاد في البالغين أحمد محمود حلمي محمد, عبد المنعم سيد راغب, محمود قدري الجندي, محمد أبو النجا محمد

\section{قسم الأثعة التثخيصية, كلية|لطب، جامعة/الأزهر}

E-mail: ahmed_helmy@gmail.com

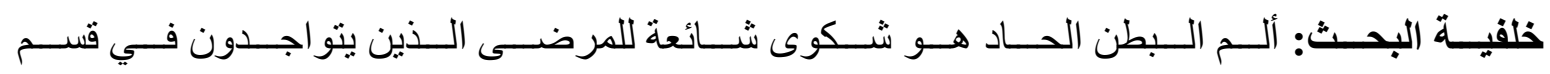

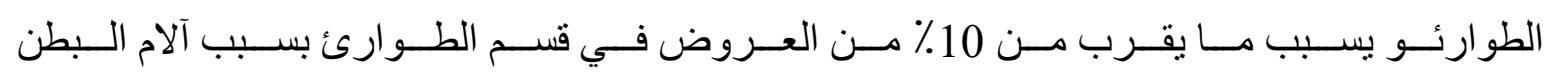

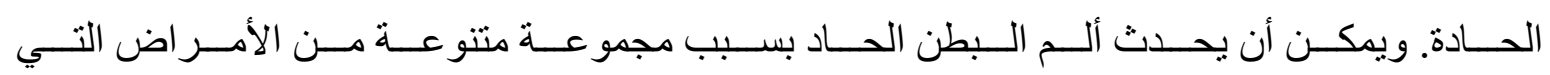

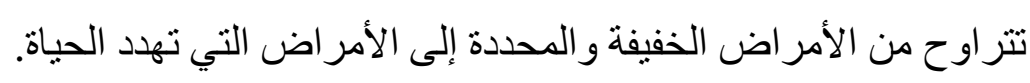

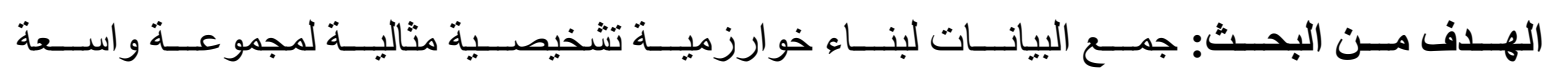
من المرضى الذين يعانون من آلام في البطن الحادة في قسم الطو الئ.

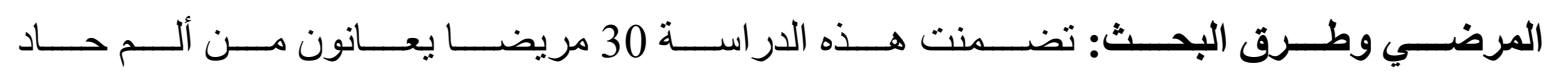

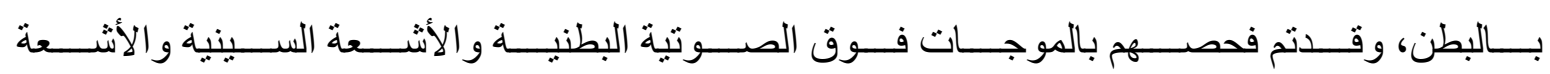

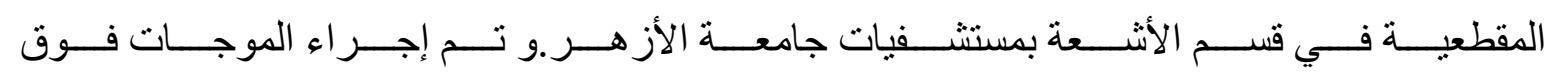

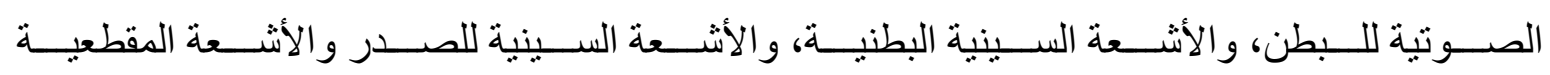

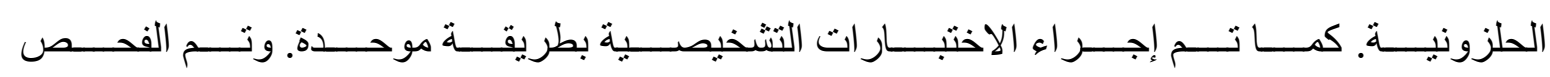

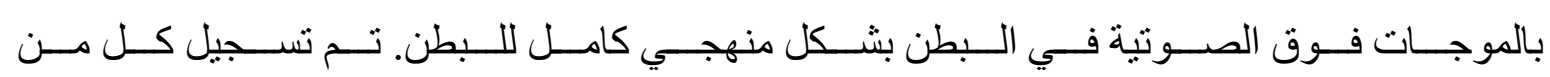
النتائج الإيجابية و السلبية لجميع المتغير ات فئ.

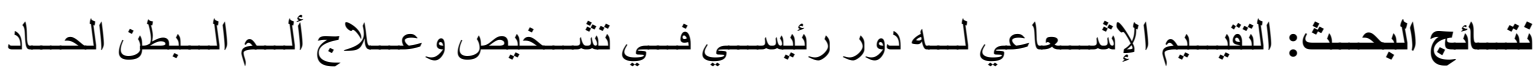
المقدم من قسم الاستقبال و الطو ارئ.

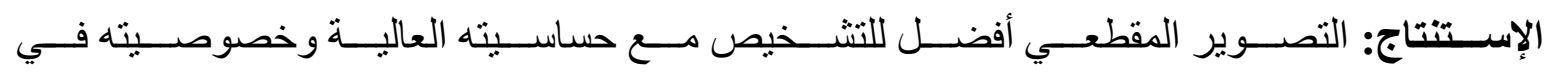

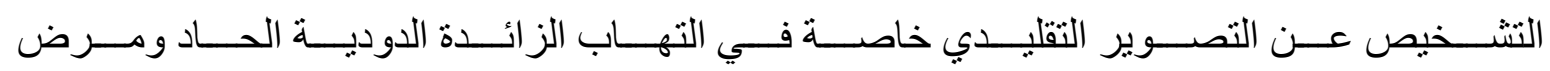

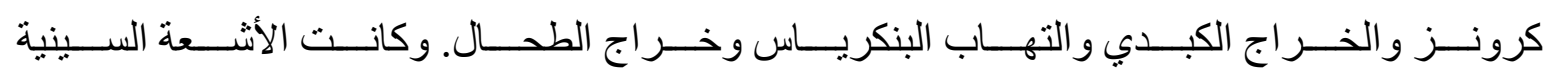
المعيار الأمثل في تشخيص الانسداد المعوي أو إنثقاب الأمعاء. 